\title{
SME in Europe Towards Local Industrial Policy Able to Sustain Innovation Ecosystems to Redesign and Reinforce Prosperity and Resilience in Post-COVID-19: Some Brief Comments
}

\author{
Luciano Pilotti \\ Department of Environmental Science and Policy, University of Milan, Italy
}

\begin{abstract}
In Europe and in the world after the crisis of 2008 (subprime and finance problems by USA) and in the current one (sanitary and health problems by China) of COVID-19 in 2020, we need a different world economics and in particular a different industrial policy starting from a more direct connections between both macro and micro perspectives and exogenous and endogenous ones, rethinking our globalization trajectories towards a more equal path supporting real economy with a responsible finance between East and West and with a hard role of European cooperation strategies for peace and health, promoting multilateralism and reducing trade and human barriers, in particular oriented to support better the development of SME in integrated networks and territories by macro-regions for new prosperity with trust, inclusion and solidarity implementing network and community innovation projects able to develop resilience. These of main topics of that work on local industrial policy in Europe in post COVID-19 crisis oriented to sustainability and responsibility with the Great Transition to Green New Deal.
\end{abstract}

Keywords: SME, European prosperity, territory, endogenous growth, local industrial policy

\section{Introduction: the Circularity Between Macro-Micro Industrial Economics After COVID-19}

At the moment in 2020 - after COVID-19-we are witnessing the obvious symptoms of a long-term stagnation for which finding "exogenous" solutions is becoming extremely complicated, from economics to politics and science to the state of democracy and where rivers of money (from ECB, EIB, World Bank, IMF or FR USA) at almost zero cost, are not sufficient-even if necessary condition - to grow in a continuous and sustainable way until we can raise the trust of consumers and investors, in particular after COVID-19. Because we need of injection of diffuse trust all over the world, between East and West indeed, democracy is dramatically put to the test in Europe as in the USA or South East Asia in an increasingly interdependent world whose fates are irretrievably intertwined and from which we must start again operating on factors of endogenous growth and for which any form of closure-as in the debate on immigration or on inter-Atlantic trade agreements-is likely to be fatal. An endogenous growth — certainly complementary and coupled with appropriate macro-economic interventions-which as regards Italy must start from the structural factors that slow down the growth of Italian productivity, which we summarize as follows:

Luciano Pilotti, Ph.D., Professor, Department of Environmental Science and Policy, University of Milan, Italy. 
(A) Supporting businesses - often too small — to grow in the network to make the most of learning and specialization economies and dynamic management of human resources and knowledge, also as a spur to internationalization processes where simple export is no longer enough;

(B) Favoring companies in "overcoming" excessive concentration on the perimeter of family resources (financial and human) by acquiring superior managerial-professional skills and resorting to financial instruments appropriate for growth, possibly separating family destinies and company destinies relying on the skills and professional markets;

(C) Feeding the exchange between productive and non-productive, efficient and inefficient companies, both to promote a renewal of skills and abilities and to look at a welfare state that looks to the workplace and not so much to the worker by liberating and overcoming that Capitalism of Relations, often "politically patronage" brokered by trade unions and professional associations;

(D) Stimulating the technological growth of companies, protected for decades by a chain of "competitive devaluations" that have slowed down their technological progress for over 25 years, to favor new hybridizations of skills and specializations from computer science to new materials to digital communication and commercial channels, crossing multiple district supply chains, growth in metropolitan areas and emerging platforms;

(E) Providing incentives for the average level of education to improve the quality of both technical and professional human capital by increasing the share of graduates in the company (and in the PA) and which can increase the quality incorporated in our products starting from scientific specializations for hybridization with the humanities, because culture is an increasingly important factor of widespread and quality creativity;

(F) Freeing from bureaucratic constraints the access to new enterprises both with reference to the regulation of the local administrations and of the central ones to fluidify the processes of new entrepreneurship, to restart the social ascension stopped in the 90s, as a spare lever social, of ideas, skills and approaches to the markets, also supporting start-ups and networks.

(G) Developing corporate awareness in the values of social responsibility towards all stakeholders and an ethics in the behaviors adopted towards the environment with a culture of product, energy and service informed by sustainability.

(H) Developing "holocratic-participatory" organizational models that overcome the traditional hierarchical models (slow, heavy and expensive) towards involvement and engagement of employees also with proximity and territorial welfare actions and promoting empathy and emotions as "strong relational vehicles".

\section{Cultures and Technical Training for Recombinant and Innovative Skills: Products as Services}

A set of levers facilitate the change of the business culture that we need to inject information and knowledge into products through "layers" of services able to connect and share networking and supply chain processes capable of regenerating creative skills for hybridization and recombination of skills. A process that can generate positive feedback on our "know-how" through the most adaptive and appropriate cycles of socio-cognitive renewal that are effective for the company, the supply chain to which it belongs and its reference context. Because in this way the company, the supply chain and the context co-strengthen and changing together, exchanging their resources and co-generating innovation as in a totipotent stem cell. A process of exchange is on the borders of our increasingly porous industrial sectors, to renew platforms and 
competitive capacities towards a company, supply chain and resilient context. Because it is now quite clear and confirmed by multiple studies that one of the sources of greatest restraint on the increase in Italian productivity is the low ability to spread innovations connected to a weak ability to integrate and absorb them, which mainly focuses on the differentials of average size of Italian companies with respect to French or German ones on the one hand and on the heterogeneity of the forms with which innovation is achieved, according to the strategic objectives, the channels used to increase the knowledge held and the types of investment, as well as to relations with the Universities and research centers that must be updated and changed. Investments in R\&D, systematic renewal of fixed capital (machinery and equipment) were adopted by a minority of companies over 10 employees as estimated by Confindustria Research Center between 2010 and 2012 (equal to 7.4\%), while for the rest of the companies and for a significant share of 38\% the formal R\&D activity was weak, confirming instead the acquisition of machinery and equipment for the renewal of fixed capital. For the remaining half of the sample there was no innovation activity. A share of companies resistant to innovation which according to the ISTAT, unfortunately seems to have strengthened between 2012 and 2014. An innovative process therefore follows mainly informal paths and very linked to the renewal of the fixed capital that certainly is not in itself sufficient to accelerate the dissemination of innovations in more systematic and shared forms (De Grauwe, 2018; Sandel, 2015).

So it is from here that we must start again with strong stimuli for the recovery of investment growth and an alignment in the forms of acquisition of innovations that the instruments put in place by the Government (super-amortization for the investments of Industry 4.0, extension and credit of tax for R\&D expenses, tax incentives for start-ups, and now with the reduction of the tax wedge in favor of workers and companies to free up consumption and investment demand resources, etc.) are dedicated to incentivating in a robust way for 2017 and 2018 which will be the test field of their effectiveness to restart productivity and competitiveness. But certainly we will need to have on the one hand the accounts in place to be credible and on the other the active investment leverage. Of this second, the Juncker Plan is only an embryonic beginning that needs to be strengthened, but that already makes us see the first (albeit tepid) effects and that Italy is using effectively even if with room for improvement. But from this point of view, it will be necessary to make the investments a permanent instrument of the European budget in a medium-long term perspective with Italy becoming the standard bearer of an arborescent New Europe, based on a common investment program (infrastructure, training, knowledge-research, safety) to attract new ones able to improve our products and services in the global competition (Mazzucato, 2020).

\section{Incentives and Industrial Endogenous Network and Platform Policies}

A set of incentives therefore allow us those eco-systemic alignments (network, supply chain, platform and multi-district) in the diffusion/acquisition of innovations, codifying in a more systematic way the relations between products, services and knowledge, between material and immaterial, between concrete and digital. Mechanisms that can allow us to raise the quality of our platforms by extending the inter-sectoral boundaries through new materials, re-engineering, innovative design, hybridization of emerging needs under the banner of radical customization modeled by digitalization. In particular, applying medium tech research in the biomedical, packaging, agro-industry, wood-furniture (from the house to the boats), software, recreational boating, sportswear and technical clothing, mechatronics, domotics, pharmaceuticals, of which we report some emerging cases that are not representative but significant for the hybridization processes (Pilotti, 2017a). In 
short, you can raise the bar of quality to make our products inimitable if the corporate culture (as described above) and the intertwining of inter-sectoral relations towards new thickening and densifications due to hybridization and generative contamination of superior variety and creativity change in an eco-systemic perspective rebuilding and reengineering product as cover by services and knowledge compatible with nature and environment, transferring between medium-large companies and SME systems, between multi-sectoral platforms and between territories, skills and know-how towards a new socio-economic, competitive and technological order, cumulatively reorienting information-knowledge towards new diversity and asymmetries, between large and small, between application ideas, between territories and between needs recomposed by new multi-centered integrations. Levers to raise our eco-systemic productivity through an increase in the rate of innovation and their diffusion in a cross-industry sense and that the push towards industry 4.0 can facilitate and strengthen the inter-sectoral networking. Roads that lead precisely to products such as services, as in the car, in the home or in tourism where the use on possession will tend to prevail more and more for an evolved user and with a widespread "digital" culture, codifying the transfer channels of the information towards a new diffusive order (Stiglitz, 2019).

In fact, according to the scheme of Hidalgo, proposed in The Evolution of the Order, we should be able to find a new order to the wealth of information and know-how that over the centuries have allowed us to become a creative, albeit messy and unequal as it is weak in the transfer of knowledge due to an excess of informality and individualism. Such as? Crossing the existing information assets channeling them to new knowledge platforms with actions of contamination and formal and codified hybridization to renew our creativity bases and continue to make good products even if more complex via servitization.

Today we are condemned to higher levels of complexity for "long" chains of progress that cannot be achieved in solitude and/or through excessively informal and hyper-local channels. We will be able to achieve this by injecting superior confidence in inter-company and inter-personal relations, overcoming selfishness, individualism and familisms that often slow down the transmission of information and knowledge useful for creating value. The family that has represented a nucleus of development-entrepreneurial and educational-fundamental of this country for centuries until the first two decades of the second post-war period, now risks representing a heavy constraint especially in the transfer of information and knowledge. For this reason, family networks should be open to "external” contributions and to the variety (of members, managerial skills and ideas) injecting confidence to renew knowledge bases to transfer useful information to innovation. Complex innovations today require greater sharing of risks on an extended basis and a "long” network-supply chain. Because we are often very good at doing - even quickly - in short networks and in contexts of creative proximity (only informally shared) but more limited and slow when we need to innovate or transfer the results because they are hampered in their sharing, especially if in team, on the net and/or in a community of subjects not characterized by family or clan ties. It is the current situation where the products are best identified through the double "layer" in the first place of the services that surround them to create and transfer them and, secondly, for the knowledge that makes it possible to innovate and transform in time and space through connectivity, accessibility, networking and shared creativity.

A question: Which participated, supportive and responsible capitalism?

The transition from 800' and 900' of a (almost) perfectly predictable Fordist capitalism in the medium term as founded on a material and fossil economy of mass production allowed first the distribution and then the gradual concentration of wealth in a few hands and yet with a risk that is gradually distributed and spread by an 
increasingly "autonomous" and (almost) independent financial capitalism. In the long phase of recent transition (last 40 years) to globalized capitalism - and to the emergence and contribution of the internet - the radical financialization of the economy has concentrated wealth even more in very few hands, reducing the risk horizons in favor of increasingly private economies concentrated to be able to "respond" to the expansion of the long and very long horizons of the intangible economy and of knowledge under the banner of "short and very short earnings, and some even stochastic (in fact speculative) against the risks medium-long term".

Diversifiable risks (short term) with a certain return against high medium-to-long term risks (for increasingly complex and structurally innovative economies and societies in terms of increasing interdependence) have led to a radical polarization of wealth. For obvious reasons: "acquiring control” at low risk on real assets by increasing the appropriated cost-value (to debt) to the increasing of the diversifiable risk within data rates, on the one hand, and on the other, abandoning non-diversifiable risk activities that they require medium-long term investment horizons and return and capital contributions beyond the privatistic return standards. Hence income inequalities between population groups, between territories, between regions, between continents, even "exchanging" capital gains against income gains, in fact, lower the average growth rates of economic systems and their technological, social and demographic rates of innovation and change. Moreover, it directly and indirectly accelerates the migration flows between countries and continents, from those with low productivity to those of high productivity and fueling a reserve industrial army and the low competition on low and medium level wages, what screwed up the crisis of demand with growing unemployment rates and lack of investments in innovative goods and services, as well as in human capital.

The objective then becomes that of "sharing medium-long term risk levels" that can accelerate the rate of change and pour resources from assets to income, making innovative activities that require decision-making horizons become attractive for widespread investment masses of medium-long term investment, first of all by raising the investment rate on quality human resources both in the old and new industrialization countries. Containing asymmetries and imbalances injected by short termism, which have extended levels of inequality by widening the gap between private remuneration and social benefits (Stiglitz, 2019; Beck, 2018). While it is a question of activating endogenous industrial policies, investing in a widespread way on AI platforms, new materials (nanotechnologies, graphene, carbon, etc.), low-cost and shared mobility infrastructures (sharing economy), development of a green economy and environmental, in non-fossil but renewable energy resources (hydrogen) in life sciences (against global health scourges, new genetic and stem cell treatments and the new personalized pharmacology), new waste industry in the perspective of circular economy. More generally, to invest in urban and non-urban systems in connective, osmotic and holistic forms with new and virtuous alliances between public and private, widening the models of widespread participation in risk towards collaboration economies and participatory management. Starting from "institutional alliances” between public and private pension funds, venture capitalists, investment funds, also through the expansion of forms of variable remuneration in relation to risks with distribution of profits and risk capital connected to performance and risk, expanding the links of non-speculative finance at the service of the economy and real societies.

A set of tools able to lower the degree of risk on medium-long term activities, reduce inequalities in access to resources, improve the quality of urban contexts, develop the widespread qualities of both technical-professional and scientific human capital , implement real and virtual networking and connectivity for widespread and balanced access to planetary resources as "common goods". New resources, skills and knowledge to be put at the service of a shared wellbeing oriented towards the qualities of a dignified living and 
of a sense of a planetary community "condemned" to pool their own destiny, as well as their own material and immaterial resources.

This requires a new ethics (between Spinoza and Kant, perhaps a post-ethical one?) (Walzer, 2020; Levinas, 1984). Capitalist in a collaborative and participatory sense and new cultures of shared production and consumption, sustainable and responsible for a thrifty, sober and supportive life, already active and today at work in the circular economy and in the sharing economy.

\section{“Beyond” the “Compassionate Capitalism” Towards Participation and Risk Sharing}

From the industrial reserve army and the captains of the nineteenth century to a widespread collaborative and shared capitalism of a planetary community of destiny, active, supportive and responsible for the XXI century. Where, however, the "compassionate" variant is no longer sufficient, as is clearly outlined by Francesco in the "Oeconomicae et pecuniarie questions", for a social economy that puts man and his needs back in the center. Moreover, the major world investors (with portfolios of over 70 trillion dollars) have subscribed to the Fundamental Principles of the UN for responsible investment choices. Thus, the Brussels European Foundation Center Conference dedicated to the development of institutional philanthropy sanctioned those basic principles towards a more equitable and supportive system, a structural antidote against all resurgent populisms and nationalisms (Urbinati, 2020; Tamir, 2020).

In fact, "Doing the Good” or "Creating Wellbeing” for people and/or the environment as such is not only a "modern" way to make business, but increasingly shows that it is a destiny needed for financial markets that look to the future. The funds with a social purpose are in great growth as are the listed companies themselves which make their social responsibility explicit with commitments in social and/or environmental utility projects, and which show performances that are clearly above the market average. Since 2010, the same social bonds have spread enormously well over the hundred in 30 countries of the capitalist West. The reasons are simple: On the one hand, a growing sensitivity of users and potential investors and/or consumers to the social issues that have raised the estimate of social impact investments to \$220 million. On the other hand, the decades-long crisis of the welfare state that has transferred growing awareness to governments in their inability to adequately finance social projects (health prevention, education, environmental preservation, poverty reduction, immigration governance, demographic trends and aging, access to digital and non-digital knowledge, etc.) and to have to push forward a renewed entrepreneurial and innovative spirit by improving the contexts of attractiveness, inclusion and human promotion. Overall, improving the distribution of risks and optimizing remuneration by reclaiming private benefits (distributed) and social benefits (widespread) and consequently reducing the range of inequality in the distribution of opportunities also with generative and corporate welfare levers where trade war can go towards new class war without a multilateral governance (Klein \& Pettis, 2020).

But these structural and behavioral impulses towards a capitalism with a "human face" cannot be separated from a structural action that changes at the root, on the one hand, the "marketism" that has accompanied the last 25 years of asymmetric globalization and that has increased imbalances and inequalities in access to resources, weakening the purchasing capacity and incomes of the lower classes but also of the middle classes, particularly at the junction between the immaterial economy and material society. In fact, on the other hand, it is a question of working with the mechanisms of functioning of the digital economy "regulating" the revolutions that have accompanied it towards non-exclusive, non-rival and cumulative goods and which 
have triggered new concentration and monopoly mechanisms, such as the Great Players of the Attention Economy (Facebook, Apple, Amazon, Microsoft, Alibaba, Incent, etc.) have shown in the last 10-15 years bypassing (or bypassing) many of the barriers (in truth, except for the Commission EU) erected by antitrust agencies from the Atlantic to the Pacific. Certainly we will have to start again from a different role of the State, as a non-neutral regulator without necessarily being more direct, because it is clear that in order to restart and innovate the Capitalizmus (as in German definition modeling of last century), we will be able not to start but towards new alliances between public and private, but also to work to mechanisms of greater participation in income and capital and therefore intervening on worn-out institutions of the property as they have been delivered to us from the 1700s onwards, and especially from the 1800s and 1900s.

\section{The "Malfunctions" of Capitalism as Structural and Non-cyclical Factors Towards a “Well-being” Without Adjectives}

It is with Deloitte (March, 2017) that we see how stakeholdership takes over the evaluation of modern companies, signaling that it will be the social impacts of companies that will impress their attractiveness for innovative investments and resources able to improve quality of life of human beings, because these impacts determine its long-term growth capacity. Or, along the same line of reflection, with the Henderson Institute of the BCG (February, 2018) which provides for the needy humanization of companies towards a lesser mechanistic technologism in favor of greater social, internal and external cohesion, looking at to the society in which the company is immersed, which also improves its long-term reputation, as well as the well-being it spreads in the environment and which it receives from the territories in which it lives and with which it interacts. In fact, many surveys also in the USA point to the preference of workers for a higher quality of organizational, management and social contexts on the goals of immediate gain. It is through a recovery of greater social cohesion that can be grafting processes of social reaggregation to update the democratic fabric fragmented by the crisis and re-undermining the consensus towards forms of protest with project and proposal, often ride irresponsibly by the new political leadership populists and sovereignists.

It is perhaps also time to better distinguish in incentive mechanisms companies that produce value or new knowledge (at no cost) from companies that merely extract value or replicable knowledge (at no cost) (Wolf, 2019; Wolf, 2020). They are operating, often with an original public contribution (Mazzucato \& Jacobs, 2017). But is it clear that part of the international debate is shifting to the need for a substantial change in ownership rights as in Corneo's recent work, Is Capitalism Obsolete? (2017), or in Viktor Mayer-Schonberger's reconstructive work, Reinventing Capitalism in the Age of Big Data.

Three conclusions of interest to the current debate of Mayer-Schonberger in relation to prices, industrial system, entrepreneurship in the impact with the ubiquitous resource of the moment big data:

Prices: For more than five centuries, prices have been the only real mechanism of regulation (more or less) negotiated of nascent markets first and consolidated then to guide the choices of end and intermediate users. Today, prices are complementary to the strategic use of platforms that through big data are better able to analyze and condition the behavior of end and intermediate consumers by crossing quality, personal tastes, durability, delivery logistics.

Industries: The physicality and logic of material scale economics have over time fostered concentration processes (including district and/or supply chain), but the network has brought back conveniences to flexible decentralisation, dynamic relocation that seemed to have disappeared. 
Entrepreneurship: As well as the global strength of the new "network masters" (from Google to Facebook to Samsung to Alibaba, etc.) is cannibalizing the innovation processes and the lattice of emerging start-ups in the mesh of an innovative process only apparently "new and modern" in a phase of fiscal and democratic weakening of the state and the resulting welfare and consensus policies (almost never informed).

It is from here that state intervention must change and start from the control on the big data networks that relates to the "public" management of personal databases and large local infrastructures and multiutilities, from energy to mobility, from education to health, from electronic communication to the competitive-collaborative environment with the "private" networks of the Great Controllers of Our Attention perched around the net and sucking systematic information from our every fraction of a second, often violating our privacy, and conditioning our choices based on the "private" use of the large databases in their possession.

It should therefore be remembered that big data is one of the strategic factors underlying the value of emerging knowledge and that fuels an increasingly shared and social innovation and that tends to revive more the use of goods (values of use) than their ownership (possession) as the collaborative economy and the sharing economy are demonstrating in car manufacturing or at home, in travel as well as in education.

\section{Business Transformations, Participatory Ownership-Management Statutes and the Italian Case: The New Pact Between Risk and Power, Between Decision-Action and Competence}

Transformations that drive radical changes in the ownership structure of companies exposed on the frontiers of knowledge and technological change better able to cope with the demand for financial resources than the capacity of the individual venture capital (single capitalist) are no longer able to sustain until the short term, for well-defined evolutionary trends and limited resources. Changes that push to favor (and promote) the ability to produce income over those of enhancement of assets, the ability to innovate over that of replication, the value of intangible knowledge on that material. And to do this we need participatory business models based on widespread and shared risk tools, involving workers and managers in the management and decision-making power of companies, along the line opened by the German Mitbestimmung with the involvement of trade unions in business boards. But that cannot stop at this form of contractual involvement and sharing of information and performance or profits in relation to productivity growth and/or performance. We need a direct extension and involvement of the assets of workers immobilised in pension funds and more generally, the risk capacity can be voluntarily assumed by the individual participants in the work of the company by holding their management skills and skills.

Therefore, a balanced rebalancing of decision-making skills and power that goes beyond the exchange of information and therefore of a new contractual and proprietary architecture. It is a new Pact between risk and power, between action and decision, between strategy and managerial practices according to "strong" and no longer residual or "weak" participatory logics capable of facing long horizons of innovation increasingly of a social nature, which seems to be a recurring theme even in Francis' recent speeches.

In the Italian case, the situation relates to swarms of SME systems that require organizational and managerial advancement in order to access advanced forms of profit and capital sharing that also pass through welding between welfare policies companies and territories that look at entire supply chains and clusters located in territorial areas and/or long homogeneous technical-productive platforms also to overcome historical limits that have still sunk. 


\section{Seven Themes for Owner-Managerial Areas of Action in the Italian Case}

The first theme is therefore certainly that of over-conditioned and short terming decisions, often resulting from a low investment in human capital with training resources inadequate to the generation of skills and skills, able to compete with planetary challenges for originality, innovation and creativity. Investment in training by Italian companies has been stuck for decades well below $1 \%$ of annual turnover and this cannot remain if we want to get on the last trains of innovation and change started well before the crisis that began in 2007-2008 with Industry 4.0.

The second theme relates to the organizational design guided by excessive "familisms and bureaucrats", unable to bring out talents and creativity, function of a management largely self-referential, weakly mobile and highly risk adverse function of a property equally immobile and driven more by heritage logic than income in the creation of value often supported by short-term horizons. Of course, the spread of objective management has been completely residual, blocked by hierarchical and rigid approaches where the concept of control has often been confused with that of command and where self-organizational and participatory factors with fiduciary proxies in the best cases to accountants or tax lawyers, losing the stimulant value of an appropriate accountability in inextricable conflicts of interest.

The third issue relates to corporate governance that moves with little external comparisons through widening of corporate perimeters, supported in medium and large enterprises by pyramid control, union pacts, para-social control agreements or etc., that is often accompanied by a very small asymmetrical capitalization compared to the desired or expected control quotas for a "capitalism (control) without capital” along the "protective lines" of the so-called "capitalism of relationship". Yet the Italian picture-at least in listed companies - is moving slowly, highlighting the epochal transition between "relationship" and "market" capitalism. In the CONSOB 2015 report, in fact, it is noted that in the last six years, while it is true that the share of the largest shareholder has remained stable on the other hand that related to "other relevant shareholders" is reduced by three points in favor of an advance from 36\% to 38\% as "presence of the market". The average participation in corporate meetings rises to about 70\% of the capital with an increase in foreign institutional investors from 13\% in 2012 to $21 \%$ today (2016), in the face of a substantial stability of Italian funds. We are still far from the structures of (Anglo-American) countries where control is contendable, the role of consolidated management, and governance led by institutional investors, directly or indirectly. The weight of international institutional funds in the assemblies of the largest listed companies has increased from $40 \%$ to $44 \%$ of the capital even with peaks reaching as high as $60 \%$ in some. On boards this has meant a greater role for minority lists and independent councillors towards the desirable set-up of contendable-controlled public companies. Union pacts still remain numerous but the "coalition capitalism" of yeslies of yestammy is once being dissolved.

The fourth theme looks at the much-vaunted praise of Italian creativity at the base of the "beautiful and well done", sometimes confused with innovations largely incremental without breakage or discontinuity with the past, more feared than brandished and seen at times in conflict with the technical-productive standards or meta-standards imposed by national and/or European authorities, paying little attention to widespread disruptive processes and the most appropriate responses. Whereas from here we will have to start again emphasizing the qualities (related to personalization, more or less radical) on quantities, promoting "horizontal, participatory and inclusive" organizational contexts capable of fostering the emergence of talents and potential organisations' creative slitabilities. Be these networks and/or communities to drive the creative empowerment 
of supply chains and platforms, cities and entire innovation regions. This increases inimitable limits and incentives for coopetition or cooperation to compete (Pilotti, 2011; Pilotti, 2014).

The fifth theme is - we could say - cultural and relates to the perceptions of the crisis and the responses that have been given to it sometimes with a kind of escape from the so-called animal spirits. Companies and entrepreneurs who during the crisis - faced with widespread deindustrialization - preferred the financial or real estate annuity rather than the (post) manufacturing and 4.0 challenges that require certain confidence in the future and clarity of objectives. A theme of "cultural weakness" has certainly been facilitated also by the crisis of politics and its ruling classes with decades of inaction and a scarcity of vision of the future for the country system, impoverishing it and forcing it out of distrust to subtraction (or abandoning) of entrepreneurship, with a reversal of the spirit that had fostered the arduous rebirth of the country in the post-war period and the revival of the 50s and 60s. Endemic undercapitalisation of SMEs, poor attention to differential qualities of human capital, women or young people, and technological and digital innovation are symptoms of these "cultural weaknesses or frailties”, ancient and/or more recent.

The sixth theme, completely across the list of those already mentioned above, relates to the nature of leadership and the processes of delegation (and corporate openness) that in the economy and knowledge society (recently driven by the widespread digitization processes of the supply chain) highlight strong evolutionary needs. All the more significant in the face of a decrease in managers in Italy, down 5\% in the period 2008-2014 and an increase of $10 \%$ in the same period to signal the choice of lower contract costs (compressed in Italy below the threshold of 120,000 euros/year), situation that pushes for a decisive openness to these frameworks in terms of career and opportunity to quickly become manager, a landing that requires a strong evolution of the entrepreneurial/managerial core originating of "driving that exerts control through the command" towards the more horizontal and osmotic one of "facilitators" of widespread processes of self-organization and self-entrepreneurship of their corporate role by all internal stakeholders. In this way, opening up spaces for young people and women, with an increase in managers and in the intellectual and scientific professions to deal with the state of deindustrialisation designed by the CEDEFOP survey (European Union, 2018a, b) to forecast employment quality at 2025. Responding in this way also to the "control crisis" made visible by the penetration of knowledge in the processes of the smart factory and strengthened in the emerging Manufacturing 4.0, also through the widespread digitization that we could say — as described by Bauman — makes the enterprise more and more fluid, or liquid. Personality and business climate weigh on efficiency as demonstrated by the Foundation for Subsidiarity in a recent study (2016) reporting that character skills/archetypes affect quality of work, structure of know-how and results. Among the five personality factors that the study highlight are also those that show that they weaken traditional approaches to control, decomposing them into:

a. Tendency to responsibility (or self-responsibility, individual and collective) or accountability;

b. Ability to open up to new experiences and skills (or learning-by-learning and co-creativity);

c. Propensity for extroversion (or involvement and exchange, experiential interaction);

d. Tendency to cooperation (or ecological working community relationship);

e. Emotional stability (transmission of empathetic intelligence and horizontal sharing to projects).

The entrepreneur-manager who welcomes these five characteristics (or a large part of them) would lead to performance increases of more than 50\% compared to those entrepreneurs-managers who remain distant. It also shows that the excess of "familism" slows down business performance, as well as what "watches too much TV" compared to other forms of horizontal information and learning. So once again, technical training and high 
training, together with a greater proximity between companies and research centres, are based on the dynamic and resilient entrepreneur. Variables that must then be crossed with those connected with the productive-sectoral and territorial identity. So an entrepreneur-manager who strongly dilutes control-command in connectivity, sharing, inclusion and the thickening of group and team relationships, reducing levels of authority and information costs in favor of innovation and creativity, better if shared.

A trajectory compatible in general with the emergence of the relief of an employeeship that can be implemented by ecological strategies of scaffolding (Pilotti, 2015), i.e., shared and voluntary participation in the objectives of the company and its network/reference chain as a "community of purpose" oriented to a social and open innovation, internal and external, both extracting private values from common goods (internalization of externality) and vice versa, outsourcing common values from private goods (externality). A new factory that learns to learn with all actors - internal and external - in search of a resilient adaptation to shocks even with the support of intelligent machines and the dialogue of enlarged communities with the transition from traditional skills to shared and distributed skills. The latter require participatory collaboration, connectivity and emotional intelligence in the service of the creativity of the entire factory as an emerging ecology interconnected with the surrounding space system and its reference environment, and hence also an openness on the issue of gender and the role of young people and women in the contribution to diversity management in the promotion of variety (internal and external). The Intelligent Factory "melts" socially in the community (societas in Latin) and vice versa the community makes shared factory in search of a new well-being and we could say, also of sustainable happiness, meaning and inclusive, with a radical work transformation as a fundamental "mutant" factor of the factory of the future in the service of a shared creativity and, also, of a civitas nova in a factory for man. Transformations that require different corporate welfare to support life career (rather than task) and levers of attractiveness of new talent. A factory that educates and trains by encouraging collaboration and a critical thought that suggests to managers things that "do not go" in addition to those that go, as a source of new creativity shared in responsibility.

The seventh theme strictly relates to the ethical values that inform the company culture and therefore to the integrity and responsibility of the top management (management and owners in particular but also of the employees all). Responsible (accountability) and ethical behaviour are the basis of good governance and a good reputation. In fact, a board of directors has the generating responsibility of reputational capital by creating all the conditions to transfer and receive ethical and responsible conduct, overseeing compliance with these values and indicating the disciplinary actions (and not only) that are made necessary in the face of violations and transgressions. Issues that should certainly involve listed companies and banks, as well as unlisted companies, to spread ethical behaviour both towards the environment and towards fundamental rights (of employees and consumers), as well as towards their partners (or competitors). This requires an increasingly strong role of independent board members to suggest, advise, control and intervene when necessary, and for this reason we also need less condescending and accommodating laws. Of course, we need a more advanced corporate culture that is sensitive to the quality of the environment, the circular economy, rights and the reduction of gender inequalities and beyond.

\section{Management/Worker Buyout: Cases of Employee Participation in Ownership and Management}

Corporate cases of participation and control by management, which we know since the 1970s in the United States, while less well-known and more recent cases of shareholding and taking control by employees 
are often in a cooperative form, sometimes in the form with the support of specialized funds and/or banks in these industrial operations. Operations now widely supported also by the European Union that incentivize this type of employee participation in the ownership and management of companies towards improving role of stakeholdership in emergent corporation as a community (Deakin, 2012).

This is the case - typical for the history and process that has been consolidated — of the Mancoop cooperative built in the countryside of Castelforte and Santi Cosma and Damiano on the border between Lazio and Campania in south of Italy as we have seen many in recent years in Europe. The generational transition or the passing of the founder who in 1957 had started the Evotape with funds from the Fund for the South. When Evotape died in 1999, Evotape began to decline like all companies that did not prepare for the generational leap and/or divestment process in time and with appropriate tools. In 2003 the acquisition of an American multinational Tyco involved in its crac was involved in the distraction of managers of large sums of money. Subsequently, the Luxembourg Fund BluO super specialized in restructuring and revitalization of medium-sized enterprises and then sold to the Mexican Alma Monta who after a few months abandoned due to the absence of a solid industrial plan. Of the 500 employees of 2000 in 2011, there remained 134 and about half decided to try the revival, also passing through years of redundancy and then investing the Tfr in the restructuring project approved by the bankruptcy curator starting to produce stickers. But by reorganizing the considerable space originating in an incubator and a small and a network of SME integrated in a Services Valley with a network of industrial partners "compatible" with the original business, from innovative start-ups, to logistics services to recreational shipbuilding up to the maintenance of tour buses and wholesale tomatoes, bringing the overall occupancy of the area back above 300 units. One of the "recovered factories" as a new process that has expanded since 2008 onwards in so many industrial crisis points and with which to restart industrial activities and demonstration that risk-taking by employees is a business option no longer marginal, Euricse, a European cooperative study centre, reports a survival rate of as much as $86 \%$ of worker-controlled enterprises, prompting the Commission to encourage this type of "corporate entrepreneurship" and transfer of labour employees, no longer as a marginal option.

Of course we need appropriate institutional tools to look strongly at these forms of widespread shareholder participation or worker buyouts, where specialist funds, pension funds and banks can act as a suitable bridge with legislation in favour, even tax, but not only, for new public-private alliances. To improve localised industrial contexts, especially where large public funds have been spent and where the presence of specialised human resources, a collaborative climate, widespread trust and a medium-to-long-term vision are required.

\section{Between State and Market “Inclusive” for New Middle Classes After Keynes and COVID's Challenges}

A widespread injection of participatory capitalism can also play an active role in countering the globalist neo-proletarianization of the lower and middle classes where motivation, skills and non-risk behaviour can be found to restart both public and private investment cycle, in particular after COVID-19, middle classes and urban proletariat who suffered the most loss of social status and access to resources with the 2008 and 2020 crisis. Starting from plans dedicated to public companies and local shareholders, as from the public companies for the exercise of an enlarged and shared control to open the selection links of new business and managerial classes on the one hand and, on the other, pushing inactive savings masses towards productive uses. Pension funds and institutional investors will need to find alternative tools for active collaboration, balancing risks, participation and power in the dynamic sharing of decisions in both large and small businesses, also looking at 
logic supply chain and clusters (Stiglitz, 2019; Beck, 2011; Beck, 2018). Expanding the basis of participation and inclusion around an active consensus to reactivate the proximity of "good politics" and CIVITAS in the government of common goods and public resources, against all abstentionism, sovereignism and populism that they hold hostage dynamic and social evolution, contemporary capitalism and that globalist neo-liberalism with double decoupling between real and financial economy and between state and market has not solved but increased with new poverty, extended inequalities and increasing information and power asymmetries. It has been shown that the relative inequalities generated by the post-war period were accompanied by growth at least until the early 1990s, gradually reducing even the absolute ones. While the growth of Western countries has been decreasing since the 1990s with an acceleration of relative inequalities, absolute growth due to emerging (former) countries (China, Russia, Brazil) has been decreasing and with this average poverty rates (Piketty, 2015). However, the "enlarged" growth of these countries has not "lifted all boats" with a growing separation between finance and the real economy and with strong speculative pressures that have emphasized the effects of inequality (and not the other way around). Since the 1990s, relative inequality rates have been higher than quantitative growth rates. To point out that we need qualitative growth and that states have proved to be the key to the greatest resistance to this "fall in average quantitative growth" by injecting social quality of innovations and supporting (Mazzucato, 2014) the sectors with the highest high productivity and higher rate of innovation from the green economy to nanotechnology, from robotics to life sciences and nutrition, from new renewable energies to agri-industry, from telecommunications to AI to fast transport in the growing collaboration between universities and markets, between public/private research centers, large companies and SME systems. With a net shift from physical to cognitive productivity (Pilotti, 2017b) also on the drive of the digital revolution entered by the transformations of Industry 4.0, in Italy, in Europe and in the world and that is changing at the root the nature of many jobs and services as of many professions (even liberal, from lawyer to accountant, from surgeon to construction engineer to industrial designer) (Colombo \& Pilotti, 2018).

In this direction, participatory capitalism can become the lever of democratic social capitalism and counteract the growing neo-proletarianization of the middle classes in the face of growing inequalities that challenge the very rules of the democracy and, therefore, civil coexistence. We must return to redistributive policies of wealth that take into account the new global context by activating the levers of a participatory capitalism because that "domandist" (high waste and heavy) is no longer sufficient, towards sustainability, sobriety and thrift in resilience.

\section{Industrial Policy, SME and Europe}

As we know, Europe is urgent and necessary to unify industrial policy oriented to promotion of SME eco-systems along four main trajectories of action, inside the "Great Transition by Green New Deal” between a century of conflict to a century of negotiation and, more recently, after the collapse of the Berlin Wall, towards collaboration.

1. Function of interaction between multiple public-private actors of cohesive communities;

2. Agglomeration of common interests via local and transnational networks;

3. Sectoral/inter-sectoral shared innovation with strong local roots;

4. Economics knowledge: networking, TLC, Internet.

In particular, we start by a focalization on knowledge based economy about three main points:

a. Central pre- and post-manufacturing phases for product and process innovation; 
b. Centrality of intangible assets (knowledge, innovation, HR, organizational and social capital, human and semantic capital) (as in the sense proposed by Floridi, 2018);

c. New actions and framework programs for innovation and knowledge.

Points developed by the 6th European Framework Program (2002-2006) as a hard integration of:

i. University-industry relations;

ii. Public research centers;

iii. Industrial technology development;

iv. Promotion of competition to encourage open innovation;

v. European Aria Research Training (AER): coordination of national and regional programs (Table 1).

A trajectory able to create an environment conducive to innovation with coherent with Lisbon's Strategy and smart specialization towards and holistic approach involving citizens, industry, the business community, municipal and county councils:

- Integration of both sectoral and inter-sectoral platform projects;

- Creation of networks of excellence: research, production and sales;

- Joining programs between the Commission and member states;

- Promoting technology transfer;

- Making risk capital available;

- Intellectual property protection;

- Human resources development;

- Social capital consolidation;

- Increasing global spending on R\&D at 3\%;

- Mobilizing actors in a triangulation between three main integrated levels—regional, national, European.

Table 1

Integration of European research area scheme

\begin{tabular}{|c|c|c|}
\hline Main topic expected needs & Structures of AER & Enforcing AER \\
\hline Genome and biotechnologies For health & Supporting by politics & Research and innovation \\
\hline Technology of information society & $\begin{array}{l}\text { Frontiers research and } \\
\text { unexpected results }\end{array}$ & Human resource/mobility Development R\&I \\
\hline $\begin{array}{l}\text { Nanotechnologies, intelligent material, } \\
\text { production process }\end{array}$ & SME and process & Research infrastructures \\
\hline Aeronautics \& Aerospace & $\begin{array}{l}\text { International of specific } \\
\text { cooperation }\end{array}$ & Science and society \\
\hline \multicolumn{3}{|l|}{ Food safety and health risks } \\
\hline Sustainable development and climate change & & \\
\hline Citizens and governance of knowledge society & & \\
\hline
\end{tabular}

Note. Source: European Commission, 2020.

It will be translated in European policy of innovation in the 7th Framework Program 2007-2013 towards 2021-2027 described in five main elements:

I. Cooperation: 2/3 resources 7th Strategic Programme in collaborative research in 10 areas (health, food, telecommunications, nanosciences/nanotechnologies, energy, climate change, transport, human sciences, space, security); 
II. Ideas: scientific research of excellence;

III. People: internal researcher mobility union;

IV. Capacity: research and knowledge society;

V. Nuclear research: nuclear fusion. Joint research center.

The core of emergent program is first of all that public demand becomes an innovation driver and, secondarily stressing the need of evolutionary approaches considering a new resource as knowledge defined as "impure" public good: not rival, not excludable, cumulative.

Consequently it is able to promote limited rationality of agents, exchange or contract does not exhaust the forms of transaction coordination. The impact on companies is clear: learns from continuous technical progress through innovation in an environment not static but dynamic. In that way, we see considerable differences in respect to traditional neoclassical approach.

The impact of technological policy underlines different points:

- Relevance of innovative eco-systems;

- Centrality of density-plurality of actors;

- Diffusive importance of innovation;

- Focus on networking processes;

- Local innovation budding from multidimensional agglomeration of institutions and actors (private and public);

- Need for transnational energy and training infrastructures (liberalizing and coordinating strategy among countries).

In case of SME industrial policy, we can see an overcoming in the subsidyzed policy of 80's and in particular with a package of actions oriented to stimulate the emergence of eco-systems in different countries of European Union, able to reinforce selection and interdependences between sector to high impact of innovation. Between them we can recall as following:

- Incentives for cooperation for the competition;

- Incentives to the quality of local contexts for endogenous growth;

- Reduction of inequalities between disadvantaged areas by promoting relations between companies in a selective manner;

- Reduction of asymmetries between high/low productivity sectors towards more technical and cognitive division of labor;

- Incentives to increase the autonomy of integrated SME systems in "networks of networks";

- Incentives for the promotion of new businesses and new markets also in the convergence between countries;

- Integration between local-national-community levels;

- SME insulation reduction with transnational development logics removing distortive conditions of competition;

- Promotion of information and innovation also through fiscal measures for sectoral/inter-sectoral integration.

Oriented to this aim European Union Commission developed a scoreboard of single area of action able to monitoring the evolution in different countries of transformations and effectiveness of incentives.

- Entrepreneurship education and training; 
- SME start-up more efficient and faster;

- Lean regulatory framework;

- Offer of skills;

- Effective online access;

- Taxation and financing;

- Single market benefits;

- Technological capacity;

- Benchmarking between member countries;

- Representation of EMS interests in the EU.

The UE trajectory overcome marginal approach to SME of 80's and 90's emphasizing local policy of industrial develop towards an endogenous framework to stimuli: A) Strengthening an industry widespread in the territory; B) Opening to transnational and multinational networks; C) Specialization of technical skills; D) Sub-supply and components with high technological content as levers of local development and of global and international markets; E) Generation of "positive externalities", economic-social-cultural for the appropriability of technological advantages; F) Integration between social, educational, human resources and territorial promotion policies.

Social cohesion policy reinforcing capabilities is able to absorb some of crisis effects after 2007-2008 and probably after pandemic of 2020.

1. Induction of cooperation from the bottom up and not only technological;

Development not only as a function of technical progress but as integration between local innovative systems.

2. Centrality of intangible assets and quality human resources for "local" contexts;

3. Centrality of universities in local systems to co-generate quality of development with Research, Innovation, Dissemination: specializing them in research and education universities (Bologna Process for collaboration between universities as the Pan-European Forum, 19 June 1999 signed by 29 countries: comparable degrees, three training levels: standard credits, student and researcher mobility);

4. Formation of the European area of research and innovation in teaching (Berlin, 2003, with 46 countries);

5. Crisis 2007-2008 and 2020 as a "destabilizing adjustment" of the change triggered by an "asymmetric and unequal globalization” that recalls more European, with both more cohesion and integration for shared prosperity: an antidote to the harmful effects of myopic emergent neo-nationalisms and sovranism silenced by pandemic but not defeated.

\section{A Brief Conclusive Comment}

Some conclusions converge after world tragedy COVID-19 towards a rethinking connection between a multiple loop between crisis and growth, consensus and democracy, technology and prosperity, individualism and community, able to overcome stagnation with industrial policy oriented to three main directions coupling with micro, macro and meso.

A. From horizontal to vertical: from widespread and non-selective incentives to the creation of "ecologically" environments favorable to attract investment by triangulation of supply chains-platforms-territory; 
B. From sectors to contexts: spatial contexts as sources of externalities "channeled" by infrastructures, training institutions for human capital and associative intermediate bodies (work and business);

C. From micro and macro to meso: relief assigned to territorial contexts as active containers of new potential emerging towards a "new manufacture" welded by networks of services and knowledge for the enhancement of networks and new leadership (of brand, market and technology).

With some more details we can say:

I. Europe and national states: horizon and context of industrial, infrastructural, sanitary and educational transformation;

II. Crisis as transition and construction: It requires change management, new perceptions of the future and potential emerging ones;

III. State and market/public and private: new alliances necessary for long-term growth;

IV. Earth, work and capital: a relationship dynamized by the role of knowledge and the penetration of science into production (physics to cognitive productivity);

V. Innovation: from localized/individualized to multifocal, systemic and social (Pilotti, 2017b);

VI. Territory and "common goods": focus loci for the emergence of ecologies of value and externalities.

We can specify tools able to display industrial policy on European territories for SME in five main transitions:

- From "measures" and "branches" and procedural logics to "agency logics": high managerial autonomy;

- From public to private: with project financing tools;

- From sectoral units to "Innovation regions": actions on multi-sectoral and multi-context interdependencies looking at centers of excellence, components and intermediate products;

- From providing incentives to process management and performance assessment (eco-systemic and sub-systemic): selection of large technological and infrastructure projects for the follow-up effects on SME systems;

- From ex-post evaluations to "approaches for objectives" of potential and their exploitation in supporting SMEs: for example through Foundations to overcome the discrepancy between family and succession (see "model of the Rhine").

An urgent trajectory is to be prepared after tragic pandemic of 2020 connecting safety, education and research investments with manufacturing territory and ecosystems by macro-regions starting from local federalism for a new interstate solidarity and collaboration able to overcome disequality and marginalization of communities and territories by open and inclusive innovation.

Four main points to recall: Europe, globalization, macro-micro economics, and savings.

About Europe, we are "condemned" to be interdependent because environmental sustainability, migration and refugee flows and financial instability are parts of a deep global imbalance and that requires global responses with more multilateral cooperation and not less, also reforming great Global Institutions (UN, OMS, IMF, NATO; BEI and UE).

Regarding globalization, we need to recover the trust of people all over the world disappointed by the effects of an asymmetric and unequal globalization that had to solve all our ills in one fell swoop, while it has increased them by increasing inequalities, increasing relative poverty and threats of global warming for which the sovereigns-nationalists that have emerged in the last 20 years have not adequately responded.

In relation to macroeconomic policies, given that we will get more indebted from this crisis and that we will be exposed for decades to the risk of financing, we will have to use it to become more efficient and lighter, 
even relying on refinancing rates below our potential growth rate, rebuilding better trading capacity in Europe and making the best use of the tools it offers us with long-term loans and secured by the European Union umbrella as we have tried to do even in the COVID-19 crisis, gaining that time which is so scarce. Acting on the one hand our private savings and on the other mobilizing the primary surplus that has been gradually improving since 1992 that do not make us identify with cicadas - as the Germans say - but with ants and connecting better macro, micro and meso policies.

About savings, we must therefore ensure that the enormous private savings are gradually geared towards productive investment even with less use of home ownership where possible and useful as fuelling a recovery in investment and growth that will then allow debt to be "normalized" also towards "common goods". That is why it is necessary to inject confidence, preventing the legacy of the pandemic crisis from being increased risk aversion as a preference for "inactive" savings due to uncertainty weighing on future returns, further slowing the recovery in productivity that has been declining for more than 25 years. We therefore need to start an industrial strategy that puts the transformation of the multiregional (and multilocal) production system at the centre by rebuilding the foundations and conditions for a new social and political development, participating and inclusive for a new risk society but in a sharing way by people, regions, cities and nations in a new emergent multilateralism.

\section{References}

Baravelli, M., Camagni, R., Marelli, E., Bellandi, M., CICIOTTI, E., Cappellin R., \& Capasso, S. (Eds.) (2017). Investimenti, Innovazione e nuove strategie di impresa. Quale ruolo per la nuova politica industriale e regionale?. Milano: Egea.

Beck, U. (2011). Conditio Humana.Ilrischionell'etàglobale. Roma: Laterza.

Beck, U. (2018). La societàglobale del rischio. Trieste: Asterios.

Békés, G., Halpern, L., Koren, M., \& Murakozy, B. (2011). Still Standing: How european firms weathered crisis. The third EFIGE policy report, Bruxelles.

Bianchi, P. (2018). 4.0 La nuova rivoluzione industrial. Bologna: Il Mulino.

Cedefop, U. (2018a). From long-term unemployment to a matching job. The role of vocational training in sustainable return to work. Report.

Cedefop, U. (2018b). Briefing note-Less brawn, more brain for tomorrow's workers: Cedefop's new skills forecast identifies parallel and contradictory trends and challenges. Report.

Chesborough, H. W. (2003). Open Innovation: The New Imperative for Creating and Profiting from Technology. Boston: Harvard Business School Press.

Colombo L., \& Pilotti L. (2018). La Rivoluzione digitale “dolce” nelle professioni liberali tra big data e artificial intelligence.

Corneo, G. (2017). Review of Is Capitalism Obsolete? A Journey through Alternative Economic System. Cambridge, MA: Harvard University Press.

De Grauwe, P. (2018). I Limiti del mercato. Da che parte oscillailpendolodell'economia?. Bologna: Il Mulino.

De Masi, D. (2018). Lavoro 2025. Il futuro dell'occupazione (e della disoccupazione). Venice: Marsilio.

Deakin, S. (2012). The Corporation as Commons: Rethinking Property Rights, Governance and Sustainability in the Business Enterprise. Queen's Law Journal, 37: 339-381.

Floridi, L. (2018). Semantic Capital: Its Nature, Value and Curation. Philosophy \& Technology, 31: 481-497.

Klein, M. C., \& Pettis, M. (2020). Trade Wars are Class wars. New Haven: Yale University Press.

Levinas, E. (1984). Etica e infinito. Ilvoltodell'altro come alteritàetica e tracciadell'Infinito. Roma: Città Nuova.

Mayer- Schonberger, V. (2018). Reinventing Capitalism in the Age of Big Data. New York: Basic Books.

Mazzucato, E. (2020). Il valore del tutto. Bari: Laterza.

Mazzucato, M. (2014). Lo Stato Innovatore. Roma: Laterza.

Mazzucato, M., \& Jacobs, M. (2017). Ripensare il capitalism. Roma: Laterza.

Piketty, T. (2015). About Capital in the Twenty-First Century. American Economic Review: Papers \& Proceedings 2015, 105(5), 48-53. http://dx.doi.org/10.1257/aer.p20151060 
Pilotti, L. (2011). Creatività, Innovazione e Territorio. Bologna : Il Mulino.

Pilotti, L. (2014). Impresa e network tra creatività, saperi e scaffolding.

Pilotti, L. (2015). Rischio, conoscenze e formazione nelle imprese del futuro. Tra auto-riforma, mutazioni camaleontiche e nuovi saperi. In Personale e Lavoro, Rivista di Cultura delle Risorse Umane. 563(1), 4-11.

Pilotti, L. (2017a). Competitività glocale, sviluppo urbano e qualità dei contesti per attrattività, creatività e innovazione. In Investimenti, Innovazione e nuove strategie di impresa. Quale ruolo per la nuova politica industriale e regionale?. Milano: Egea.

Pilotti, L. (2017b). Produttività cognitiva e Politiche Industriali Locali. Berlin: EAI.

Pilotti, L., Ganzaroli, A., \& De Noni, I. (2014). Il Cammino Infinito.

Rullani, F., \& Rullani, E. (2018). Dentro la rivoluzione digitale - Per una nuova cultura d'Impresa e del Management. Torino: Giappichelli.

Sandel, M. (2015). Quelcheisoldi non possonocomprare - i limiti morali del mercato. Milano: Feltrinelli.

Sennet, R. (1999a). L’uomo flessibile: le conseguenze del nuovo capitalismo sulla vita personale. Milano: Feltrinelli.

Sennet, R. (1999b). La cultura del nuovo capitalism. Milano: Il Mulino.

Stiglitz, J. (2019). People, Power, and Profits: Progressive Capitalism for an Age of Discontent. New York: W W Norton.

Tamir, Y. (2020). Le ragioni del Nazionalismo. Milano: Unibocconi.

Tinagli, I., \& Florida, R. (2005). L'Italia nell'era creative. Milano: Creativity Group Europe.

Treu, T. (2016). Introduzione welfare aziendale. WP 297/2016, Centre for the Study of European Labour Law "MASSIMO D'ANTONA”, University of Catania.

Urbinati, N. (2020). Me the People - How Populism Transform Democracy. Cambridge, MA: Harvard University Press.

Walzer, M. (2020). Esodo e Rivoluzione. Universale Economica Feltrinelli.

Wolf, M. (2019). Why Rigged capitalism is damaging liberal democracy. Retrieved from www.ft.com

Wolf, M. (2020). Democracy will fail if we don't think as citizens. Retrieved from www.ft.com 